\title{
Long-term oncological outcomes of low anterior resection for rectal cancer with and without preservation of the left colic artery: a retrospective cohort study
}

Yuwen LuO ${ }^{1,2 \dagger}$, Rongjiang $\mathrm{Li}^{3+}$, Deqing $\mathrm{Wu}^{2 \dagger}$, Jun Zeng ${ }^{3+}$, Junjiang Wang ${ }^{1,2}$, Xianzhe Chen ${ }^{1,2}$, Chengzhi Huang ${ }^{2,4}$, Yong $\mathrm{Li}^{1,2,4,5}$ and Xueqing $\mathrm{YaO}^{1,2,4,5^{*}}$

\begin{abstract}
Background: There is uncertainty in the literature about preserving the left colic artery (LCA) during low anterior resection for rectal cancer. We analyzed the effect of preserving the LCA on long-term oncological outcomes.

Methods: We retrospectively collected clinicopathological and follow-up details of patients who underwent low anterior resection for rectal cancer in the General Surgery Department of Guangdong Provincial People's Hospital, from January 2014 to December 2015. Cases were divided into low ligation (LL), LCA preserved, or high ligation $(\mathrm{HL}), \mathrm{LCA}$ not preserved, of the inferior mesenteric artery. The 5-year overall survival (OS) and disease-free survival (DFS) rates were compared between the two groups.

Results: Altogether, there were 221 and 295 cases in the LL group and HL groups, respectively. Operating time in the LL group was significantly longer than in the HL group (224.7 vs. $211.7 \mathrm{~min}, p=0.039$ ). Postoperative 30-day mortality, early complications including anastomotic leakage showed no significant differences between the $L L$ and $\mathrm{HL}$ groups (postoperative 30-day mortality, $0.9 \% \mathrm{LL}, 1.4 \% \mathrm{HL}, p=0.884$; early complications, $41.2 \% \mathrm{LL}, 38.3 \% \mathrm{HL}, p=$ 0.509 ; anastomotic leakage $8.6 \% \mathrm{LL}, 13.2 \% \mathrm{HL}, p=0.100$ ). The median follow-up periods were $51.4(7-61)$ months in the LL group and 51.2 (8-61) months in the HL group. During follow-up, the percentages of patients who died, had local recurrence, or had metastases were 39.8, 7.7, and 38.5\%, respectively, in the LL group and 39, 8.5, and 40\%, respectively, in the $\mathrm{HL}$ group; these differences were not significant (all $p>0.05$ ). The 5-year OS and DFS were 69.6 and $59.6 \%$ in the LL group, respectively, and 69.1 and $56.2 \%$ in the HL group, respectively; these differences were not significant (all $p>0.05$ ). After stratification by tumor-node-metastasis stage, the difference between the 5 -year OS and DFS for stages I, II, and III cancer were not significant (all $p>0.05$ ).

(Continued on next page)
\end{abstract}

\footnotetext{
* Correspondence: syyaoxueqing@scut.edu.cn

†Yuwen Luo, Rongjiang Li, Deqing Wu and Jun Zeng contributed equally to

this work.

${ }^{1} T$ The Second School of Clinical Medicine, Southern Medical University,

Guangzhou 510082, People's Republic of China

2Department of General Surgery, Guangdong Provincial People's Hospital,

Guangdong Academy of Medical Sciences, Guangzhou 510080, People's

Republic of China

Full list of author information is available at the end of the article
}

\section{$\triangle B M C$}

(c) The Author(s). 2021 Open Access This article is licensed under a Creative Commons Attribution 4.0 International License, which permits use, sharing, adaptation, distribution and reproduction in any medium or format, as long as you give appropriate credit to the original author(s) and the source, provide a link to the Creative Commons licence, and indicate if changes were made. The images or other third party material in this article are included in the article's Creative Commons licence, unless indicated otherwise in a credit line to the material. If material is not included in the article's Creative Commons licence and your intended use is not permitted by statutory regulation or exceeds the permitted use, you will need to obtain permission directly from the copyright holder. To view a copy of this licence, visit http://creativecommons.org/licenses/by/4.0/ The Creative Commons Public Domain Dedication waiver (http://creativecommons.org/publicdomain/zero/1.0/) applies to the data made available in this article, unless otherwise stated in a credit line to the data. 
(Continued from previous page)

Conclusions: The long-term oncological outcomes of $L L$ group are comparable with HL group. LL cannot be supported due to the absence of lower complication rates and the longer operating times.

Keywords: Rectal cancer, Left colic artery, Inferior mesenteric artery, Long-term oncologic outcomes

\section{Background}

Colorectal cancer is the third most diagnosed cancer in men and the second in women [1]. In recent years, colorectal cancer management includes surgery supplemented by radiotherapy and chemotherapy $[2,3]$. Anatomically, the colon and rectum have distinct locations, blood supply, drainage and innervation. These differences result in dissimilarities in the invasive growth of the primary tumor as well as surgical approaches and treatment outcomes [4]. Rectal cancer surgery is methodically more complex, and the surgical demands increase with the depth of the aboral tumor position and proximity to the sphincter muscle $[5,6]$. During low anterior resection for rectal cancer, the inferior mesenteric artery (IMA) can be treated in two ways: one is to identify and preserve the left colic artery (LCA) while ligating the IMA after bifurcation of the LCA, and the other is to directly ligate the root of the IMA without preserving the LCA [7]. According to Bertrand's study [8, 9], the branches of the IMA are subject to wide interindividual variation making it difficult, if not impossible, to replicate surgery based on anatomy. It is thought that preserving the LCA maintains a better blood supply [10], which leads to a lower anastomotic leakage rate [11]. However, this technique may lead to greater anastomotic tension, prolonged operation time, and more technical challenges [6].

Many studies, including meta-analyses, suggest that preserving the LCA may reduce the incidence of anastomose-related complications but has no effect on the long-term oncologic outcomes [10-13]. A randomized, multicenter, controlled trial showed that low ligation (LL) of the IMA in laparoscopic rectal cancer surgery resulted in better genitourinary function preservation without affecting initial oncological outcomes, while high ligation (HL) of the IMA did not increase the anastomotic leak rate [14]. However, laparotomy cases were excluded, and the effects of high or low ligation of the IMA on long-term oncologic outcomes were not reported. In Fujii's study [15], laparotomy cases were included, and the results showed that the IMA ligation level was unrelated to anastomotic leakage. Further, there was no significant difference observed in the longterm outcomes in patients with or without LCA preservation. Since the benefits of LCA preservation are still debatable, we analyzed the data obtained from patients who underwent low anterior resection for rectal cancer in the General Surgery Department of Guangdong Provincial People's Hospital to evaluate whether preservation of the LCA affected the early complication rate and long-term oncologic outcomes.

\section{Methods}

\section{Patients}

Inclusion criteria: (1) 18 years of age and over; (2) low anterior resection for rectal cancer; (3) postoperative pathological diagnosis of rectal adenocarcinoma; and (4) informed consent signed prior to surgery. Exclusion criteria: (1) recurrent rectal cancer; (2) emergency surgery; (3) preoperative and intraoperative detection of distant organ metastases or extensive implantation metastases in the abdominal cavity; (4) palliative surgery; (5) a postoperative pathology report that showed residual cancer cells at the proximal or distal resection margin; (6) no standard chemotherapy for tumor-node-metastasis (TNM) staging II or III after surgery; (7) synchronous colorectal carcinoma and other organ tumors; and (8) incomplete case data.

Based on the above criteria, we retrospectively collected data from the medical records of patients who had a low anterior resection for rectal cancer at Guangdong Provincial People's Hospital, from January 2014 to December 2015. A total of 516 from 635 cases were included in this study; in 221 cases, the LCA was preserved intraoperatively, while in the remaining 295 cases, the LCA was not preserved.

\section{Surgical procedure}

All patients underwent total mesorectal excision, or partial mesorectal excision, plus D3 lymph node dissection with sphincter preservation [16]. For the HL group, the IMA was ligated and divided $2 \mathrm{~cm}$ from its origin. The inferior mesenteric vein was ligated and divided below the pancreatic margin. For the LL group, the LCA was identified and preserved while low ligation of the IMA (the superior hemorrhoidal artery) was performed. Lymphadenectomy was performed medially along the IMA until reaching $2 \mathrm{~cm}$ from the aorta. After resection of the tumor, the bowel proximal to the pubic symphysis was checked to ensure it was free of tension. Splenic flexure mobilization was performed if the bowel was not free. To reconstruct the gastrointestinal tract, an end-to- 
end colorectal anastomosis was made. If the surgeon thought it was necessary, based on a technical evaluation of the quality of the anastomosis, a diverting ileostomy was added.

\section{Postoperative adjuvant chemotherapy}

Patients with stage II or III adenocarcinoma were treated with the XELOX regimen (oxaliplatin, capecitabine) of chemotherapy for six to eight courses after surgery.

\section{Surgical parameters and postoperative follow-up}

Surgical parameters recorded were: operation time, presence of splenic flexure mobilization, intraoperative complications, 30-day postoperative mortality, 30-day postoperative complications (classified as mild or severe; Clavien-Dindo classification $\leq$ II was considered a mild complication, $\geq$ III was considered a severe complication), anastomotic level from the anal verge, anastomotic leak classification (according to the standard of The International Study Group of Rectal Cancer, ISREC. In simple terms, Grade A anastomotic leakage results in no change in patients' management, whereas grade B leakage requires active therapeutic intervention but is manageable without re-laparotomy and Grade $\mathrm{C}$ anastomotic leakage requires re-laparotomy [17]), length of distal margin, number of lymph nodes harvested, and the number of positive lymph nodes.

Periodic patient follow-up with office visits for 5 years: every 3-6 months for 2 years after surgery; every 6-12 months for 3 to 5 years after surgery; once a year for 5 years after surgery. The follow-up visit included a physical examination, carcinoembryonic antigen measurement, a computed tomography scan, and colonoscopy. Confirmation of recurrence required imaging or pathological evaluation.

\section{Statistical analyses}

Statistical analyses were performed using SPSS (Statistical Product and Service Solutions version 22.0 for Windows, Armonk, NY, USA: IBM Corp). Quantitative data were described using the mean \pm standard deviation, and t-tests or rank sum tests were used to test the hypothesis. Categorical data were described by the number of cases and percentages, and Chi-square $(\mathrm{X} 2)$ or Fisher's exact tests were used to test the hypothesis. The KaplanMeier method was used to estimate survival, and the log-rank test was used to evaluate differences between the survival curves. Statistical significance was considered to exist when $p<0.05$.

\section{Results}

Patient clinical characteristics

A total of 516 rectal cancer patients, including 346 (67.1\%) men and 170 (32.9\%) women, were enrolled in this study. Of these cases, 221 (42.8\%) were in the LL group and 295 (57.2\%) were in the HL group. The clinicopathological characteristics of the two groups are provided in Table 1 . There were no statistically significant differences between the two groups with regards to sex, age, body mass index (BMI), tumor location, neoadjuvant therapy, or postoperative adjuvant treatment.

\section{Surgical outcomes}

The surgical outcomes and early complications are presented in Table 2. The operating time in the LL group was significantly longer than that of the HL group (224.7 $\mathrm{min}$ vs. $211.7 \mathrm{~min}$, respectively; $p=0.039$ ). There was no significant difference in operative bleeding between the LL and HL groups $(76 \mathrm{ml}$ vs. $70 \mathrm{ml}$, respectively; $p=0.252$ ). Splenic flexure mobilization in the LL group was significantly higher than that in the HL group ( $13.1 \%$ vs. $6.1 \%$, respectively; $p=0.006)$. The rate of protective ileostomies in the LL group was 29.9 and $24.1 \%$ in the HL group $(p=0.140)$, which showing no significant difference. The anastomotic level from the anal verge in the LL group was $5.9 \pm 2.0 \mathrm{~cm}$, and in the $\mathrm{HL}$ group was $5.6 \pm 2.1 \mathrm{~cm}(p=0.418)$. The 30 -day postoperative mortality was $0.9 \%$ in the LL group and $1.4 \%$ in the HL group $(p=0.884)$. In the LL group, 29.0 and $12.2 \%$ experienced mild and severe complications, respectively, while in the HL group, 26.4 and $11.9 \%$ experienced mild and severe complications, respectively ( $p=$ 0.788). Anastomotic leakage occurred in 2.3 and $1.8 \%$ of ISREC grade $B$ and $C$ cases, respectively, in the LL group and 2.4 and $2.4 \%$ of ISREC grade B and C cases, respectively, in the HL group $(p=0.202)$. Reoperation occurred in $1.8 \%$ of the LL group and $2.4 \%$ of the HL group ( $p=$ $0.691)$.

\section{Pathology outcomes}

The pathology outcomes are presented in Table 3. The length of the distal margin in the LL group was $2.6 \pm 0.7$ $\mathrm{cm}$ and was $2.7 \pm 0.8 \mathrm{~cm}$ in the HL group $(p=0.429)$. The number of lymph nodes harvested in the LL group was $18.8 \pm 9.6$ and was $17.0 \pm 6.6$ in the HL group ( $p=$ 0.111). The number of positive lymph nodes and tumors as per TNM staging was not significantly different between the two groups (all $p>0.05$ ).

\section{Follow-up outcomes}

The Long-term outcomes are presented in Table 4. Altogether, $91.5 \%$ patients completed follow-up in the LL group, median follow-up time was 51.4 (7-61) months, and $89.2 \%$ patients completed follow-up in the HL group, median follow-up time was 51.2 (8-61) months. During follow-up, the numbers of patients who died, had local recurrence, or had metastases were 88 (39.8\%), 17 (7.7\%), and 85 (38.5\%), respectively, in the 
Table 1 Patient Clinical Characteristics at Baseline

\begin{tabular}{|c|c|c|c|}
\hline & $\begin{array}{l}\mathrm{HL} \\
(n=295)\end{array}$ & $\begin{array}{l}\mathrm{LL} \\
(n=221)\end{array}$ & $P$ value \\
\hline $\operatorname{Sex}[n(\%)]$ & & & 0.732 \\
\hline Male & $196(66.4)$ & $150(67.9)$ & \\
\hline Female & 99 (33.6) & $71(32.1)$ & \\
\hline Age: years & $63.3 \pm 10.7$ & $64.4 \pm 9.8$ & 0.471 \\
\hline BMI: $\mathrm{kg} / \mathrm{m}^{2}$ & $22.3 \pm 3.0$ & $22.4 \pm 3.1$ & 0.832 \\
\hline ASA classification & & & 0.117 \\
\hline । & $151(51.2)$ & $97(43.9)$ & \\
\hline$\|$ & $101(34.2)$ & $78(35.3)$ & \\
\hline III & $43(14.6)$ & $46(20.8)$ & \\
\hline Preoperative Hb: $\mathrm{g} / \mathrm{L}$ & $129.7 \pm 11.4$ & $131.6 \pm 10.7$ & 0.285 \\
\hline Preoperative Alb: g/L & $34.8 \pm 3.4$ & $35.0 \pm 3.5$ & 0.657 \\
\hline Tumor location [n (\%)] & & & 0.459 \\
\hline Upper rectum $^{\text {a }}$ & $77(26.1)$ & $66(29.9)$ & \\
\hline Middle rectum ${ }^{\mathrm{b}}$ & $133(45.1)$ & $101(45.7)$ & \\
\hline Lower rectum $^{c}$ & $85(28.8)$ & $54(24.4)$ & \\
\hline Neoadjuvant therapy ${ }^{d}[\mathrm{n}(\%)]$ & $65(22.0)$ & $46(20.8)$ & 0.739 \\
\hline Postoperative adjuvant treatment [n (\%)] & $89(30.2)$ & $71(32.1)$ & 0.634 \\
\hline
\end{tabular}

Abbreviations: BMI Body mass index, Hb Hemoglobin, Alb Albumin, HL High ligation, LL Low ligation, ASA classification American Society of

Anesthesiologists Classification

a $>10 \mathrm{~cm}$

b $10-5 \mathrm{~cm}$

c $<5 \mathrm{~cm}$

${ }^{d}$ Neoadjuvant chemotherapy or neoadjuvant chemoradiotherapy

LL group and 115 (39.0\%), 25 (8.5\%), and 118 (40.0\%), respectively, in the HL group. The differences were not significant (all $p>0.05$ ).

There were no significant differences in the 5-year OS and DFS (69.6\% vs.69.1\%, $p=0.942$, and $59.6 \%$ vs. $56.2 \%$, $p=0.570$, respectively) between the $\mathrm{LL}$ and the $\mathrm{HL}$ groups, as analyzed by the Kaplan-Meier method (Fig. 1). We performed further analyses of stage-by-stage OS and DFS in stages I to III cases. There were no statistically significant differences between the LL and HL groups for these stages (Fig. 2).

\section{Discussion}

Since Heald et al. proposed total mesorectal excision in 1982, the clinical outcomes of middle and low rectal cancer have significantly improved [18, 19]. This improvement is mainly due to reduced local recurrence [20]; however, anastomotic leakage is still an important factor affecting the short and long-term postoperative outcomes of rectal cancer, in addition to increasing the total cost of treatment [21-23]. It has been reported that the incidence of anastomotic leakage after rectal cancer surgery is between 5 and 26\% [24, 25]. To date, no consensus has been reached on whether LCA preservation during rectal cancer surgery can reduce anastomosis- related complications and improve long-term prognosis $[13,26]$.

Excessive anastomotic tension and poor blood supply are crucial factors for anastomotic leakage [27]. High ligation of the IMA, at its aortic origin, allows a $9 \mathrm{~cm}$ gain of length over low ligation [28]. However, after high ligation, the proximal colon can only supply blood from the middle colic artery (a branch of the superior mesenteric artery), reducing blood perfusion of the marginal arterial arch, and disrupting the blood supply to the terminal colon [29].

Anastomotic leakage is one of the most common serious complications of rectal cancer surgery. There are many factors affecting anastomotic leakage including: the patient's age, BMI, nutritional status, comorbidities, tumor location, neoadjuvant radiotherapy, anastomotic blood supply, and anastomotic tension [30-32]. The results of our study showed that anastomotic leakage occurred in 19 (8.6\%) patients in the LL group and in 39 (13.2\%) patients in the HL group. This difference was not statistically significant. Moreover, there were no statistically significant differences in anastomotic bleeding and anastomotic stenosis between the two groups. However, a meta-analysis [12], containing 17 studies with 6247 patients, showed that preserving the LCA was 
Table 2 Surgical outcomes and early complications

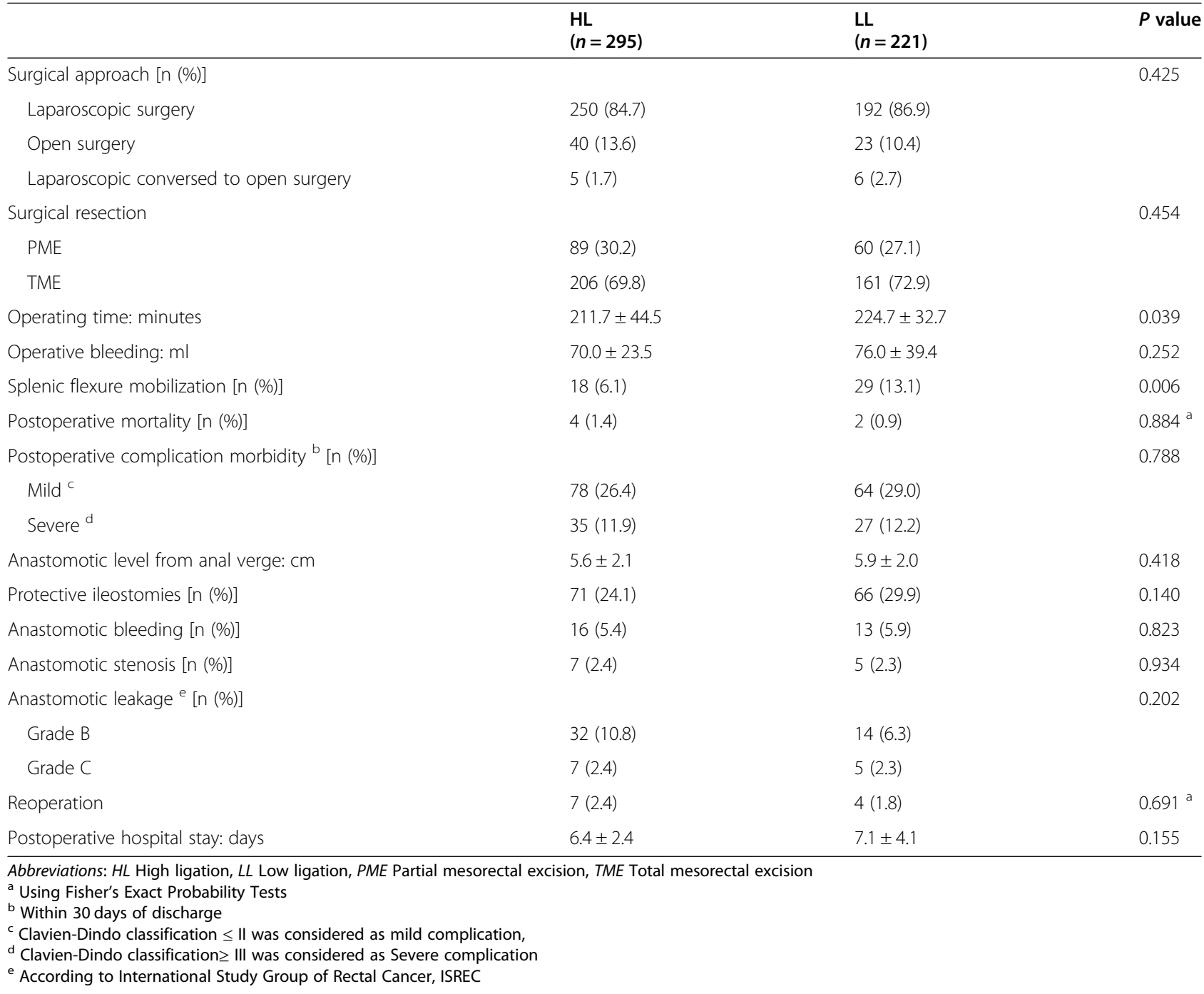

associated with reduced anastomotic leakage rate (odds ratio $=0.78,95 \%$ confidence interval $(\mathrm{CI}): 0.62-0.98, p=$ 0.03 ). Our study may not have shown this as it was retrospective, only ISREC grade $\mathrm{B}$ or $\mathrm{C}$ anastomotic leaks could be traced back and analyzed.
Intraoperative parameters and postoperative complication rates are important indices for demonstrating the quality control of a surgical procedure. A randomized controlled trial showed that LCA preservation did not increase the duration of surgery of low anterior resection

Table 3 Pathology Outcomes

\begin{tabular}{|c|c|c|c|}
\hline & $\begin{array}{l}\mathrm{HL} \\
(n=295)\end{array}$ & $\begin{array}{l}\mathrm{LL} \\
(n=221)\end{array}$ & $P$ value \\
\hline Distal margin: $\mathrm{cm}$ & $2.7 \pm 0.8$ & $2.6 \pm 0.7$ & 0.429 \\
\hline Number of lymph nodes harvested & $17.0 \pm 6.6$ & $18.8 \pm 9.6$ & 0.111 \\
\hline Number of stage III positive lymph nodes & $4.0 \pm 1.9$ & $3.9 \pm 1.9$ & 0.810 \\
\hline Tumor TNM ${ }^{a}$ staging & & & 0.807 \\
\hline । & $39(13.2)$ & $26(11.8)$ & \\
\hline$\|$ & $126(42.7)$ & $92(41.6)$ & \\
\hline ॥ा & $130(44.1)$ & $103(46.6)$ & \\
\hline
\end{tabular}

Abbreviations: HL High ligation, LL Low ligation 
Table 4 Long-term results

\begin{tabular}{llll}
\hline & $\begin{array}{l}\text { HL } \\
(\boldsymbol{n}=\mathbf{2 9 5})\end{array}$ & $\begin{array}{l}\text { LL } \\
(\boldsymbol{n}=\mathbf{2 2 1})\end{array}$ & $\boldsymbol{P}$ value \\
\hline Follow-up time: month (min-max) & $51.2(8-61)$ & $51.4(7-61)$ & 0.887 \\
5-year overall survival rate & & & \\
All stages & $69.1 \%$ & $69.6 \%$ & 0.942 \\
Stage I & $91.3 \%$ & $85.7 \%$ & 0.633 \\
Stage II & $75.9 \%$ & $75.0 \%$ & 0.955 \\
Stage III & $56.5 \%$ & $61.4 \%$ & 0.657 \\
5-year disease-free survival rate & & & \\
All stages & $56.2 \%$ & $59.6 \%$ & 0.570 \\
Stage I & $77.4 \%$ & $80.0 \%$ & 0.796 \\
Stage II & $62.1 \%$ & $66.7 \%$ & 0.512 \\
Stage III & $44.6 \%$ & $49.3 \%$ & 0.753 \\
Loss of follow-up [n (\%)] & $32(10.8)$ & $21(9.5)$ & 0.618 \\
Local recurrence [n (\%)] & $25(8.5)$ & $17(7.7)$ & 0.748 \\
Tumor metastasis [n (\%)] & $118(40.0)$ & $85(38.5)$ & 0.723 \\
Death [n (\%)] & $115(39.0)$ & $88(39.8)$ & 0.848 \\
\hline Abbreviations: HL High ligation, LL Low ligation & &
\end{tabular}

for rectal cancer [14]; however, our study revealed that the mean operating time of the LL group was significantly longer than that of the HL group. This could be due to the higher rate of splenic flexure mobilization in the LL group, prolonging the operative time for the whole group (13.1\% in the LL group vs $6.1 \%$ in the HL group, $p=0.006$ ). Despite the prolonged operation time in the LL group, there was no significant difference in operative bleeding between the two groups. Over $85 \%$ of the procedures were laparoscopic surgeries, with only a $2.1 \%$ conversion from laparoscopic to open surgery. After passing the laparoscopic learning curve, intraoperative bleeding does not increase significantly as the surgical area expands [33].
IMA root lymph nodes are the third station of lymphatic drainage in rectal cancer and the most important route of metastasis in progressive rectal cancer [34]. Studies have shown that IMA root lymph node metastases have a negative impact on patients' 5-year survival and tumor recurrence rates [35]. In our study, the differences between the number of lymph nodes harvested and the number of positive lymph nodes were not statistically significant between the two groups, suggesting that the surgical approach of preserving the LCA, i.e., IMA low level ligation, does not reduce the harvesting and positivity rate of lymph nodes.

Regarding the long-term outcomes in patients, survival analysis showed that low anterior resection for rectal cancer with or without LCA preservation showed no statistically significant difference in the 5-year OS and DFS (LL group vs. HL group: $69.6 \%$ vs. 69.1 and $59.6 \%$ vs. $56.2 \%$, respectively). Further analysis of stage-by-stage OS and DFS in stage I to stage III cases showed no statistically significant difference between LL and HL groups. Several previous studies have also shown that LCA preservation compared to non-preservation showed no significant differences with respect to the 5-year mortality in patients who underwent laparoscopic rectal cancer surgery, and this comparable success came with acceptable safety outcomes $[10,12,13]$. Data from the Japan Clinical Oncology Group Study showed that if the LCA was preserved, 5-year relapse-free survival (RFS) and OS were better than in the LCA non-preservation group (RFS: 83.7 and $80.5 \%$, hazard ratio $(H R)=0.80$, 95\% CI: $0.51-1.26$, OS: 96.3 and $91.1 \%, \mathrm{HR}=0.41,95 \%$ CI: 0.19-0.89) [36]. Another Japanese study by Fujii [15] showed that the IMA ligation level was unrelated to anastomotic leakage and there was no significant difference in the long-term results between low and high ligation of the IMA. Recent meta-analyses support this

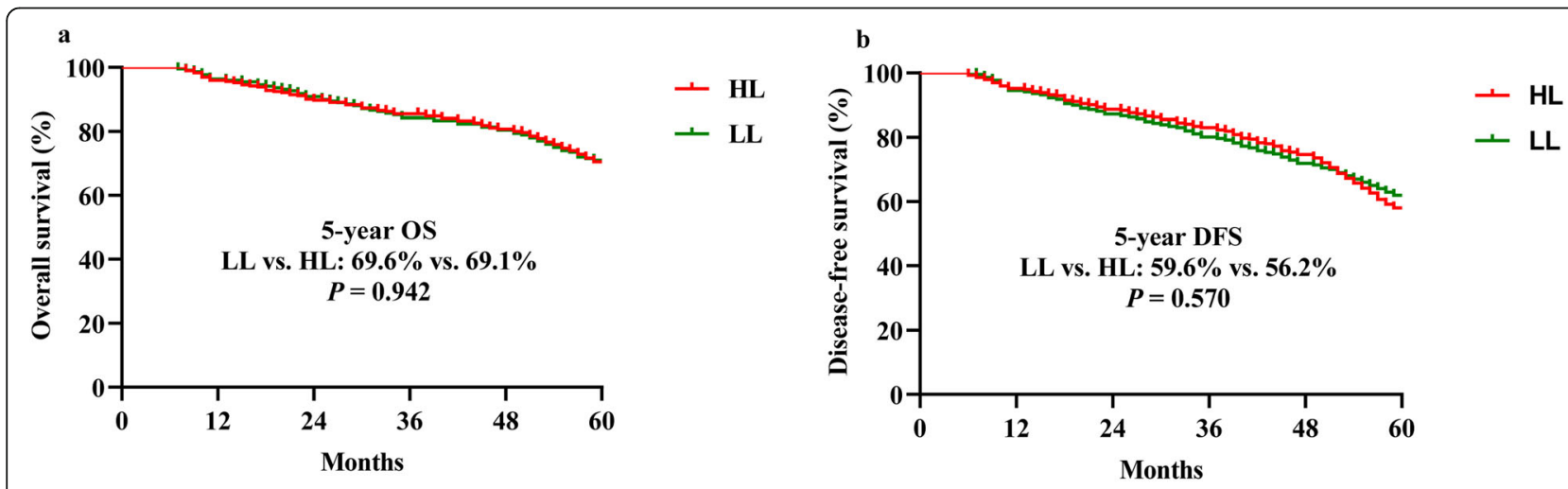

\section{All Stages}

Fig. 1 Kaplan-Meier estimates of overall survival and disease-free survival for all anterior resection cases (a and $\mathbf{b}$, respectively). Abbreviations: LCA, left colic artery; HL: high ligation; LL: low ligation 


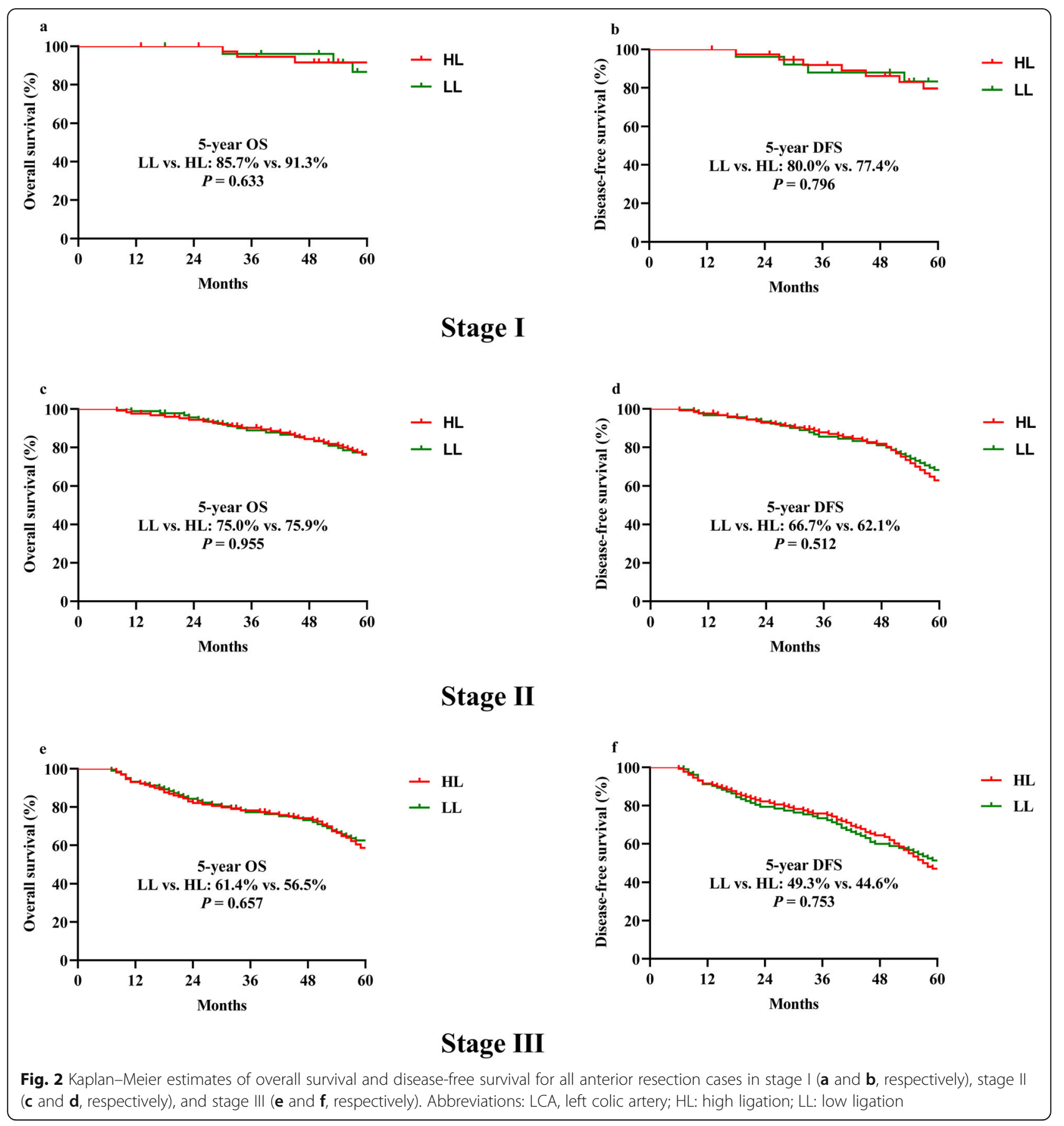

finding $[11,12]$. However, one meta-analysis, which included 3119 patients in five cohorts, pooled HR results showing a significant OS benefit of high ligation over low ligation ( $\mathrm{HR}=0.77,95 \% \mathrm{CI}$ : 0.66-0.89) [37].

Our study has certain limitations. First, this is a single-institution retrospective study, and of the 635 cases, 119 cases had missing data and were removed from the analysis. Second, Omission of circumferential resection margin positivity/negativity assessment is a weakness since this is a crucial factor that influences long-term oncological results [38]. Third, choice of surgical implemented procedure could vary between surgeons thus leading to bias in our results. Finally, there may be differences in the standards of neoadjuvant and adjuvant chemotherapies between western countries and China, which could result in diverse outcomes among patients from different countries. 


\section{Conclusions}

The results of this single-center retrospective study suggest that the early complication rates and longterm oncologic outcomes associated with LCA preservation in low anterior resection of rectal cancer are comparable with those associated with ligation of the artery at the origin of the IMA. Preserving LCA cannot be supported due to the absence of lower complication rates and the longer operating times. However, further multicenter randomized controlled trials are required to confirm the validity of these results in a broader context.

\section{Abbreviations \\ LCA: Left colic artery; IMA: Inferior mesenteric artery; HL: High ligation; LL: Low ligation; OS: Overall survival; DFS: Disease free survival; TNM: Tumor node, and metastasis; BMI: Body mass index; ISREC: The International Study Group of Rectal Cancer; Cl: Confidence interval; RFS: Relapse free survival; HR: Hazard ratio}

\section{Acknowledgements}

We thank Editage company for their professional writing services.

\section{Authors' contributions}

(I) Conception and design: XQY; (II) Administrative support: The Ethics Committee of Guangdong Provincial People's Hospital; (III) Provision of study materials or patients: DQW, JJW, YL; (IV) Collection and assembly of data: YWL, RJL, DQW, JZ; (V) Data analysis and interpretation: YWL, XZC, CZH; (VI) Manuscript writing: All authors; (VII) Final approval of manuscript: All authors.

\section{Funding}

This work was supported by grants from the Science and Technology Planning Project of Guangdong Province, China (No. 2017A030223006, 2016A020215128), the Science and Technology Planning Project of Guangzhou, China (No. 201704020077), the Second Batch of Scientific Research Projects of Dengfeng Plan (NO. DFJH201913), the Research Fund of CSCO-Roche Oncology (NO. Y-2019Roche-190), the Research Fund of CSCOHansoh Oncology (NO. Y-HS2019/2-050), the Research Fund of Guangdong General Hospital (No. y012015338), and the Yuexiu Science and Information Center of Guangzhou Scientific Foundation (No. 2012-GX-046). The funding bodies played no role in the design of the study and collection, analysis, and interpretation of data and in writing the manuscript.

\section{Availability of data and materials}

The datasets used and/or analyzed during the current study are available from the corresponding author on reasonable request.

\section{Ethics approval and consent to participate}

This study was approved by the Ethics Committee of Guangdong Provincial People's Hospital [No. GDREC2019296H(R1)] and was carried out in adherence with the Declaration of Helsinki.

The need for informed consent from all patients was waived due to the study's retrospective nature.

The data that support the findings of this study are available from the corresponding author upon reasonable request.

\section{Consent for publication}

Not applicable.

\section{Competing interests}

The authors declare that they have no competing interests.

\section{Author details}

${ }^{1}$ The Second School of Clinical Medicine, Southern Medical University, Guangzhou 510082, People's Republic of China. ²Department of General Surgery, Guangdong Provincial People's Hospital, Guangdong Academy of Medical Sciences, Guangzhou 510080, People's Republic of China. ${ }^{3}$ Department of General Surgery, Baoan Central Hospital, The Fifth Affiliated hospital of Shenzhen University, Shenzhen 518000, People's Republic of China. ${ }^{4}$ School of Medicine, South China University of Technology, Guangzhou, Guangdong 510006, People's Republic of China. ${ }^{5}$ School of Biology and Biological Engineering, South China University of Technology, Guangzhou, Guangdong 510006, People's Republic of China.

Received: 5 August 2020 Accepted: 27 January 2021

Published online: 17 February 2021

\section{References}

1. Bray F, Ferlay J, Soerjomataram I, Siegel RL, Torre LA, Jemal A. Global cancer statistics 2018: GLOBOCAN estimates of incidence and mortality worldwide for 36 cancers in 185 countries. CA Cancer J Clin. 2018;68(6):394-424.

2. Lakkis Z, Manceau G, Bridoux V, Brouquet A, Kirzin S, Maggiori L, de Chaisemartin C, Lefevre JH, Panis Y. Management of rectal cancer: the 2016 French guidelines. Colorectal Dis. 2017;19(2):115-22.

3. Berho M, Narang R, Van Koughnett JA, Wexner SD. Modern multidisciplinary perioperative management of rectal cancer. JAMA Surg. 2015;150(3):260-6.

4. Paschke S, Jafarov S, Staib L, Kreuser ED, Maulbecker-Armstrong C, Roitman M, Holm T, Harris CC, Link KH, Kornmann M. Are colon and rectal cancer two different tumor entities? A proposal to abandon the term colorectal cancer. Int J Mol Sci. 2018;19(9):2577.

5. Pox C, Aretz S, Bischoff SC, Graeven U, Hass M, Heußner P, Hohenberger W, Holstege A, Hübner J, Kolligs F, et al. S3-guideline colorectal cancer version 1.0. Zeitschrift fur Gastroenterologie. 2013;51(8):753-854.

6. Raab HR. R1 resection in rectal cancer. Der Chirurg; Zeitschrift fur alle Gebiete der operativen Medizen. 2017:88(9):771-6.

7. Patroni A, Bonnet S, Bourillon C, Bruzzi M, Zinzindohoué F, Chevallier JM, Douard R, Berger A. Technical difficulties of left colic artery preservation during left colectomy for colon cancer. Surg Radiol Anat. 2016;38(4):477-84.

8. Zaborowski A, Stakelum A, Winter DC. Systematic review of outcomes after total neoadjuvant therapy for locally advanced rectal cancer. Br J Surg. 2019; 106(8):979-87.

9. Bertrand MM, Delmond L, Mazars R, Ripoche J, Macri F, Prudhomme M. Is low tie ligation truly reproducible in colorectal cancer surgery? Anatomical study of the inferior mesenteric artery division branches. Surg Radiol Anat. 2014:36(10):1057-62.

10. Guo Y, Wang D, He L, Zhang Y, Zhao S, Zhang L, Sun X, Suo J. Marginal artery stump pressure in left colic artery-preserving rectal cancer surgery: a clinical trial. ANZ J Surg. 2017;87(7-8):576-81.

11. Yang $X$, Ma P, Zhang X, Wei M, He Y, Gu C, Deng X, Wang Z. Preservation versus non-preservation of left colic artery in colorectal cancer surgery: an updated systematic review and meta-analysis. Medicine. 2019;98(5):e13720.

12. Fan YC, Ning FL, Zhang CD, Dai DQ. Preservation versus non-preservation of left colic artery in sigmoid and rectal cancer surgery: A meta-analysis. Int J Surg (London, England). 2018;52:269-77.

13. Cirocchi R, Trastulli S, Farinella E, Desiderio J, Vettoretto N, Parisi A, Boselli C, Noya G. High tie versus low tie of the inferior mesenteric artery in colorectal cancer: a RCT is needed. Surg Oncol. 2012;21(3):e111-23.

14. Mari GM, Crippa J, Cocozza E, Berselli M, Livraghi L, Carzaniga P, Valenti F, Roscio F, Ferrari G, Mazzola M, et al. Low ligation of inferior mesenteric artery in laparoscopic anterior resection for rectal Cancer reduces genitourinary dysfunction: results from a randomized controlled trial $(\mathrm{HIGH}$ LOW trial). Ann Surg. 2019;269(6):1018-24.

15. Fujii S, Ishibe A, Ota M, Suwa H, Watanabe J, Kunisaki C, Endo I. Short-term and long-term results of a randomized study comparing high tie and low tie inferior mesenteric artery ligation in laparoscopic rectal anterior resection: subanalysis of the HTLT (high tie vs. low tie) study. Surg Endosc. 2019:33(4):1100-10.

16. Watanabe T, Itabashi M, Shimada Y, Tanaka S, Ito Y, Ajioka Y, Hamaguchi T, Hyodo I, Igarashi M, Ishida $\mathrm{H}$, et al. Japanese Society for Cancer of the Colon and Rectum (JSCCR) guidelines 2014 for treatment of colorectal cancer. Int J Clin Oncol. 2015;20(2):207-39.

17. Rahbari NN, Weitz J, Hohenberger W, Heald RJ, Moran B, Ulrich A, Holm T, Wong WD, Tiret E, Moriya $Y$, et al. Definition and grading of anastomotic leakage following anterior resection of the rectum: a proposal by the international study Group of Rectal Cancer. Surgery. 2010;147(3):339-51.

18. Lacy AM, Tasende MM, Delgado S, Fernandez-Hevia M, Jimenez M, De Lacy B, Castells A, Bravo R, Wexner SD, Heald RJ. Transanal Total Mesorectal excision for rectal Cancer: outcomes after 140 patients. J Am Coll Surg. 2015;221(2):415-23. 
19. Heald RJ, Husband EM, Ryall RD. The mesorectum in rectal cancer surgery-the clue to pelvic recurrence? Br J Surg. 1982;69(10):613-6.

20. Kitz J, Fokas E, Beissbarth T, Ströbel P, Wittekind C, Hartmann A, Rüschoff J, Papadopoulos T, Rösler E, Ortloff-Kittredge P, et al. Association of Plane of Total Mesorectal excision with prognosis of rectal Cancer: secondary analysis of the CAO/ARO/AIO-04 phase 3 randomized clinical trial. JAMA surgery. 2018;153(8):e181607.

21. McDermott FD, Heeney A, Kelly ME, Steele RJ, Carlson GL, Winter DC. Systematic review of preoperative, intraoperative and postoperative risk factors for colorectal anastomotic leaks. Br J Surg. 2015;102(5):462-79.

22. Parthasarathy $M$, Greensmith $M$, Bowers $D$, Groot-Wassink T. Risk factors for anastomotic leakage after colorectal resection: a retrospective analysis of 17 518 patients. Colorectal Dis. 2017;19(3):288-98.

23. Vu L, Penter C, Platell C. Long-term significance of an anastomotic leak in patients undergoing an ultra-low anterior resection for rectal cancer. ANZ J Surg. 2019;89(10): 1291-5.

24. Peeters KC, Tollenaar RA, Marijnen CA, Klein Kranenbarg E, Steup WH, Wiggers T, Rutten HJ, van de Velde CJ. Risk factors for anastomotic failure after total mesorectal excision of rectal cancer. Br J Surg. 2005;92(2):211-6.

25. Vlot EA, Zeebregts CJ, Gerritsen JJ, Mulder HJ, Mastboom WJ, Klaase JM. Anterior resection of rectal cancer without bowel preparation and diverting stoma. Surg Today. 2005:35(8):629-33.

26. Hinoi T, Okajima M, Shimomura M, Egi H, Ohdan H, Konishi F, Sugihara K, Watanabe M. Effect of left colonic artery preservation on anastomotic leakage in laparoscopic anterior resection for middle and low rectal cancer. World J Surg. 2013;37(12):2935-43.

27. Tanaka J, Nishikawa T, Tanaka T, Kiyomatsu T, Hata K, Kawai K, Kazama S, Nozawa $\mathrm{H}$, Yamaguchi $\mathrm{H}$, Ishihara S, et al. Analysis of anastomotic leakage after rectal surgery: A case-control study. Ann Med Surg (2012). 2015;4(2): 183-6.

28. Girard E, Trilling B, Rabattu PY, Sage PY, Taton N, Robert Y, Chaffanjon P, Faucheron $J$ L. Level of inferior mesenteric artery ligation in low rectal cancer surgery: high tie preferred over low tie. Tech Coloproctol. 2019;23(3):267-71.

29. Seike K, Koda K, Saito N, Oda K, Kosugi C, Shimizu K, Miyazaki M. Laser Doppler assessment of the influence of division at the root of the inferior mesenteric artery on anastomotic blood flow in rectosigmoid cancer surgery. Int J Color Dis. 2007;22(6):689-97.

30. Cirocchi R, Farinella E, Trastulli S, Desiderio J, Di Rocco G, Covarelli P, Santoro A, Giustozzi G, Redler A, Avenia N, et al. High tie versus low tie of the inferior mesenteric artery: a protocol for a systematic review. World J Surg Oncol. 2011;9:147.

31. Lee SY, Jung MR, Kim CH, Kim YJ, Kim HR. Nutritional risk screening score is an independent predictive factor of anastomotic leakage after rectal cancer surgery. Eur J Clin Nutr. 2018;72(4):489-95.

32. Shinji S, Ueda Y, Yamada T, Koizumi M, Yokoyama Y, Takahashi G, Hotta M, Iwai T, Hara K, Takeda K, et al. Male sex and history of ischemic heart disease are major risk factors for anastomotic leakage after laparoscopic anterior resection in patients with rectal cancer. BMC Gastroenterol. 2018;18(1):117.

33. Tekkis PP, Senagore AJ, Delaney CP, Fazio WW. Evaluation of the learning curve in laparoscopic colorectal surgery: comparison of right-sided and leftsided resections. Ann Surg. 2005;242(1):83-91.

34. Rao X, Zhang J, Liu T, Wu Y, Jiang Y, Wang P, Chen G, Pan Y, Wu T, Liu Y, et al. Prognostic value of inferior mesenteric artery lymph node metastasis in cancer of the descending colon, sigmoid colon and rectum. Colorectal Dis. 2018;20(6):01350142.

35. Kim JC, Lee KH, Yu CS, Kim HC, Kim JR, Chang HM, Kim JH, Kim JS, Kim TW. The clinicopathological significance of inferior mesenteric lymph node metastasis in colorectal cancer. Eur J Surg Oncol. 2004;30(3):271-9.

36. Akagi T, Inomata M, Hara T, Mizusawa J, Katayama H, Shida D, Ohue M, Ito M, Kinugasa Y, Saida Y, et al. Clinical impact of D3 lymph node dissection with left colic artery (LCA) preservation compared to D3 without LCA preservation: exploratory subgroup analysis of data from JCOG0404. Ann Gastroenterol Surg. 2020:4(2):163-9.

37. Singh D, Luo J, Liu XT, Ma Z, Cheng H, Yu Y, Yang L, Zhou ZG. The longterm survival benefits of high and low ligation of inferior mesenteric artery in colorectal cancer surgery: a review and meta-analysis. Medicine. 2017; 96(47):e8520.

38. Nagtegaal ID, Quirke P. What is the role for the circumferential margin in the modern treatment of rectal cancer? J Clin Oncol. 2008;26(2):303-12.

\section{Publisher's Note}

Springer Nature remains neutral with regard to jurisdictional claims in published maps and institutional affiliations.

Ready to submit your research? Choose BMC and benefit from:

- fast, convenient online submission

- thorough peer review by experienced researchers in your field

- rapid publication on acceptance

- support for research data, including large and complex data types

- gold Open Access which fosters wider collaboration and increased citations

- maximum visibility for your research: over $100 \mathrm{M}$ website views per year

At BMC, research is always in progress.

Learn more biomedcentral.com/submissions 